\title{
Costumbres Culinarias de la Sierra Ecuatoriana
}

\section{Culinary Costums of the Ecuadorian Highlands}

\author{
Ana Matilde Moreno Guerra. ${ }^{1}$, Ronald Mauricio Zurita Gallegos. ${ }^{2} \&$ Jessica Alexandra \\ Robalino Vallejo. ${ }^{3}$
}

Recibido: 10-05-2020 / Revisado: 15-06-2020 /Aceptado: 04-07-2020/ Publicado: 03-08-2020

\begin{abstract}
.
DOI: https://doi.org/10.33262/concienciadigital.v3i3.1.1442

The present research is originated as a result of a Gastronomy career project at the Escuela Superior Politécnica de Chimborazo called "Register of Culinary Traditions of Riobamba canton, as part of its Intangible Cultural Heritage. The main objective is to identify customs of the rural town, Licán, based on its festive agro calendar in order to safeguard traditions and culinary practices. An analysis was carried out from the general to the particular by using the deductive method, as well as the inductive, through ethnographic techniques such as: bibliographic review (historical documents, territorial development plans), interview to quality informants (town community leaders, senior citizens). In addition to the observation, life stories and workshops with focal groups. Licán is one of eleven rural towns of Riobamba canton, province of Chimborazo. The population, mainly adult, is established in its ancestor customs, traditions and diets. The gastronomic customs of Licán are characterized by their relationship with festivals, traditions, rituals, religion, myths, dishes with cultural backgrounds linked to past times, harvests and sowings. The world of gastronomy is made up of an extensive variety of cultures and customs. In Licán some of the festivities that currently survive have been transmitted from generation to generation, it is celebrated in different months of the year, where its culinary practices are highlighted. Through research, the conservation of some traditions that survive, as constitutive elements of the intangible cultural heritage of the parish, is confirmed.
\end{abstract}

\footnotetext{
${ }^{1}$ Escuela Superior Politécnica de Chimborazo, Facultad Salud Pública, Carrera de Gastronomía. Riobamba, Ecuador. amoreno_g@espoch.edu.ec

${ }^{2}$ Escuela Superior Politécnica de Chimborazo, Facultad Salud Pública, Carrera de Gastronomía.

Riobamba, Ecuador. ronald.zurita@espoch.edu.ec

3 Escuela Superior Politécnica de Chimborazo, Facultad Salud Pública, Carrera de Gastronomía. Riobamba, Ecuador.jrobalino@espoch.edu.ec
} 
Keywords: Customs, gastronomy, Licán, traditions, culture, heritage.

\section{Resumen.}

La presente investigación surge a raíz del proyecto de la carrera de Gastronomía de la Escuela Superior Politécnica de Chimborazo denominado "Registro de Tradiciones Culinarias del cantón Riobamba, como parte de su Patrimonio Cultural Inmaterial. El objetivo principal es identificar costumbres gastronómicas de la parroquia rural Licán basadas en el calendario agro festivo con fines de salvaguarda de las tradiciones. Se realizó un análisis de lo general a lo particular, utilizando el método deductivo, así como el método inductivo mediante el uso de técnicas etnográficas como: La revisión bibliográfica (documentos históricos, planes de desarrollo territorial), entrevista a informantes de calidad (líderes parroquiales, comunitarios, adultos mayores). Además, la observación participante, historias de vida y los talleres con grupos focales. Licán constituye una de las once parroquias rurales del Cantón Riobamba de la provincia de Chimborazo. La población, principalmente adulta, se halla arraigada a las costumbres, tradiciones y alimentación de sus antepasados. Las costumbres gastronómicas de Licán se caracterizan principalmente por su relación con las fiestas, tradiciones, ritos, religión, mitos, platos con antecedentes culturales ligados a tiempos pasados, cosechas y siembras. El mundo de la gastronomía está constituido por una extensa variedad de culturas y costumbres. En Licán algunas de las festividades que actualmente perviven han sido transmitidas de generación en generación, y se celebra en diferentes meses del año, donde se resaltan sus prácticas culinarias. Mediante la investigación, se constata la conservación de algunas tradiciones que sobreviven como elementos constitutivos del patrimonio cultural inmaterial de Licán.

Palabras claves: Tradiciones, gastronomía, Licán, tradiciones, cultura, patrimonio.

\section{Introducción.}

El presente estudio surge a raíz del proyecto de investigación denominado "Registro de Tradiciones Culinarias del cantón Riobamba, como parte de su Patrimonio Cultural Inmaterial" mediante un convenio entre: la Carrera de Gastronomía de la Escuela Superior Politécnica de Chimborazo (ESPOCH), la Dirección de Gestión Turística del Gobierno Autónomo Descentralizado Municipal del cantón Riobamba y la Casa de la Cultura Ecuatoriana núcleo de Chimborazo. El objetivo principal es identificar costumbres de la parroquia rural Licán basadas en el calendario agro festivo con fines de salvaguarda de las tradiciones y prácticas culinarias.

Esta investigación se caracteriza, además de una revisión bibliográfica y documental, por la participación de la comunidad y sus representantes, en calidad de agentes testimoniales de saberes; a partir de lo cual se levanta y sistematiza la información. Las costumbres gastronómicas junto con sus técnicas culinarias ancestrales de la parroquia, es el inicio de todo un proceso, por medio del cual, se constata la conservación de algunas tradiciones que sobreviven como elementos constitutivos de su patrimonio cultural inmaterial. 


\section{Metodologia.}

La investigación realizada se fundamentó en la deducción (Münch \& Angeles , 2015), partiendo de hechos generales para buscar la explicación de situaciones concretas vinculadas a la investigación, se analizaron los aspectos más relevantes de la parroquia Licán con el propósito de entender las tradiciones y prácticas culinarias basadas en el calendario agro festivo. Por otro lado, el método inductivo fue aplicado mediante el uso de técnicas etnográficas donde, "el proceso de la investigación es flexible y no existe un esquema rígido" (Bernal , 2016), como: La revisión bibliográfica (documentos históricos, planes de desarrollo territorial), entrevista y otros.

La entrevista se aplicó a informantes de calidad (líderes parroquiales, comunitarios, adultos mayores). Además, la observación participante, las historias de vida y los talleres con grupos focales; que favorecieron el análisis cualitativo, el mismo que permitió un mejor acercamiento con la comunidad y a su vez la franqueza en la entrega de información.

\section{Resultados.}

\section{Parroquia rural Licán}

El choque de los dos mundos, español e indígena, produjo, desde el inicio de la conquista, el cruce de razas, dándole a la población de lo que hoy es Ecuador una configuración muy especial. Los descendientes de españoles e indígenas constituyen la población más numerosa del país, ubicada en todas sus regiones naturales. En sus manifestaciones culturales, se observan claramente los elementos que corresponden a la influencia de uno o de otro grupo humano.

La ciudad de Riobamba se fundó el 14 de agosto de 1534 por Diego de Almagro en Liribamba conocida como la capital de los Puruháes, lo que hoy es Sicalpa y Cajabamba denominada Villa la Unión, Cantón Colta. El 4 de febrero de 1797 un terremoto destruyó la Villa de San Pedro de Riobamba matando alrededor de 10.00 personas, mientras que en abril de 1799 el presidente de la real audiencia de Quito, Barón de Carondelet ordena que, los habitantes de la destruida Villa se trasladen a lo que en ese entonces se conocía como la llanura de Tapi territorio de la parroquia Licán.

Licán tiene como significado piedra pequeña (Freire, 2005, p. 89). Constituye una de las once parroquias rurales del Cantón Riobamba de la provincia de Chimborazo (Tipán \& Cando, 2017), está situada geográficamente en el centro del territorio continental ecuatoriano, lugar de grandes contrastes físicos, económicos y culturales. Este territorio fue asiento de los Puruháes, valerosos y amantes de la libertad, aguerridos luchadores contra sus opresores por la defensa de los derechos de sus pueblos (Freire, 2005, p. 36).

Con la forma de un polígono irregular. La parroquia rural Licán se encuentra a una distancia de $6 \mathrm{Km}$ de la cabecera provincial. Limitado por la parroquia de San Andrés del cantón Guano y la parroquia Calpi del Cantón Riobamba al Norte, las parroquias Lizarzaburu y Veloz del Cantón Riobamba al sur, la parroquia Lizarzaburu al este y al oeste las parroquias Cacha y 
Calpi del Cantón Riobamba (GADPL, 2020). En el año de 1990 en la parroquia Licán residían 5.534 habitantes, para el año 2010, la población se incrementa a 7.963 habitantes (INEC, 2010), por asentamientos humanos de otras parroquias. La población de la parroquia Licán es mayoritariamente mestiza representando el $80,11 \%$, y solamente el $16,82 \%$ es indígena (INEC, 2010).

El antiguo pueblo de Licán estuvo organizado antiguamente en Ayllus y parcialidades como los: Macají, Baliscán, Gausi, entre otros; a los que se le sumaron los; Ananchanga, Andaguilla, Lurinchanga y Mayos, que llegaron del Cuzco en calidad de mitimaes traídos por el Inca (Aguiló, 1985). Los araucanos llegaron con los Incas encabezados por Túpac Yupanqui y fundaron Licán delegando a Cuxi Argos como gobernador. Posteriormente Leandro Sepla y Oro, fue entre 1764 y 1803 curaca principal y gobernador de Licán y Macají, quienes tenían un manuscrito en lengua Puruhuay, que contenía información acerca de la historia de los antepasados (PDOT Parroquia Lican, 2012). En época de los incas realizaban varias fiestas, entre ella la fiesta de la Inca Palla o Curi Paccha llamada también Guaminga.

Para el año de 1902 se fundó la primera escuela de la parroquia, institución que se ha constituido en el semillero de la formación de muchas generaciones con notables representantes.Durante los primeros años del siglo anterior la parroquia Licán se detuvo en el tiempo, y es a partir de la década de los 40 que empieza nuevamente a percibir los signos del progreso, con la presencia de notables Licáneños como Don Moisés Castañeda a quien se debe a construcción del primer canal de agua de riego, la construcción del tanque de recolección y la pila que proveía agua (tomada del canal, sin potabilización) para el consumo doméstico.

Otro ilustre Licáneño que se destaca en el manteniendo de la disciplina y el orden fue el Sr. Julio Ruiz en su calidad de juez de campo administrando justicia y a la vez nominando a los alcaldes (personas del barrio San José de Macají), personajes encargados del cuidado del orden, y la práctica de buenos modales. Un sitial importante en esta reseña merece el Sr. Lui A. Barahona, en su función como educador, que no solo, se preocupó del adelanto material de la parroquia, sino que, sobre todo, dedicó especial esmero a la formación intelectual de la niñez de aquel entonces, hoy prestantes ciudadanos. Además de ser el impulsor, para que por primera vez, en Licán, se culturice la fiesta del carnaval con comparsas y desfiles. Licán no solo es conocida en el contexto nacional e internacional por sus hechos históricos, sino por las páginas brillantes de su palmarés como la cultura, el folklor muy admirado por propios y extraños, sus fiestas, su gastronomía y por el aporte musical de grandes compositores y artistas que han llenado de orgullo a este rincón patrio.

\section{Costumbres Gastronómicas según el calendario agro-festivo}

Es posible considerar a las comidas como cotidiana, especial y ceremonial. Una comida cotidiana no marca situaciones sociales que tienen que ver con ciclos ceremoniales denominados por los ritos de pasaje (como la primera comunión, un casamiento, una muerte religiosa). La comida especial no tiene connotaciones rituales, pero significa un alimento fuera de lo común, el cual refleja una mayor inversión de esfuerzo y tiempo en su elaboración. 
Finalmente, el alimento ceremonial está rodeado de una serie de implicaciones sociales y rituales y demuestra el punto más alto de la preocupación culinaria (Carrillo, 1996)

Las fiestas de los pueblos aborígenes del Ecuador, a veces, se confunden con aquellas que impusieron los Incas durante su dominio (Moreno, Bustos L, Terán, \& Landázurí, 2008). La fiesta religiosa es un tema poco desarrollado dentro de la literatura antropológica andina, la mayor parte de dichos estudios ha girado en torno al sentido semántico y simbólico de los mitos y los ritos indígenas (Küper, 1997). En Licán algunas de las festividades que actualmente perviven han sido transmitidas de generación en generación, se la celebra en diferentes meses del año, donde se resaltan sus prácticas culinarias.

\section{Enero: Fiesta de los Santos Reyes Magos}

La fiesta tradicional de los Santos Reyes es planificada durante un año y la organización se basa en la historia de los devotos que gira alrededor de la imagen religiosa. El "Niño Rey de Reyes" es la conmemoración religiosa más grande, la organización de la fiesta es patrimonio de los fundadores y jochantes. Inicia con la designación de los priostes, los jochantes y los guashayos. La fiesta intensifica las relaciones de amistad entre familiares y vecinos. La relación entre todos estos elementos sociales es muy fraterna y adquiere compromisos formales (Cisneros, 2017).

La fiesta de los Santos Reyes Magos se caracteriza por un conjunto de actividades donde participan personajes típicos de los desfiles, procesiones magos, reyes, embajadores junto con juegos pirotécnicos, la disertación de las Loas. Cada año se elige los priostes para la fiesta del siguiente año (Universidad de Texas, 2017). Al culminar el último día de la novena, generalmente el 5 de enero; se sirve a los acompañantes: caldo de gallina, arroz con carne de cerdo y pollo junto con un vaso de café (Urquizo A, 2017). . El día 6 de enero, el prioste recibe en su casa a la gente visitante, dando la bienvenida con un "abreboca" particular de casi todas las festividades: Mote con fritada.

Durante el transcurso del día se sirve caldo de gallina, arroz con papas en salsa de maní y lechuga; sobre las papas se coloca un pedazo de cuy y de conejo horneado, cuyo sabor se debe a un aliño a base de: ajo, cebolla paiteña, sal, achiote, entre otros. Adicional se sirve una salsa picante realizada con tomate de árbol previamente hervido y pelado, ají molido, cebolla y sal. Además, se ofrece una bebida muy tradicional para los Licáneños: chicha de jora, la misma que se elabora con dos días de anticipación.

Entre las tres de la tarde, se brinda "chocolatito caliente". Una bebida con chocolate en tableta, agua, azúcar y una pizca de sal. Las tabletas de chocolate son traídas con anticipación desde la ciudad de Ambato, siendo una costumbre de algunos años atrás, menciona el señor Pedro Brito (presidente del GAD parroquial de Licán), quien aclara que es el único producto que se trae de otra ciudad.

La misma comida especificada arriba, se lo sirve al siguiente día (7 de enero) para celebrar "La Tomina". Es un agradecimiento a los colaboradores conocidos como "jochantes" (Camas, 2014) de la fiesta (personas que ofrendan productos para la preparación de la comida) y se 
reúnen para realizar la deshierba de los terrenos del prioste (Urquizo A, 2017), participan exclusivamente los vasallos (quienes acompañan en el baile con los caballitos junto al rey), el rey, la gringa y las mujeres de los vasallos, las cuales preparan con anterioridad el chocolate caliente con pan. Además, es muy común que se sirva un vaso con "come y bebe" (bebida a base de frutas picadas).

\section{Febrero: Fiesta del Carnaval}

El carnaval es organizado por el GAD parroquial el 27 y 28 de febrero. En esta festividad, los oriundos de Licán realizan preparaciones especialmente para comercializar como: Chigüiles, hornado con mote, fritada con mote; las dos acompañadas de tortillas con salsa de maní. También, preparan chochos con maíz tostado en paila, cebollas y sal. El taita carnaval es considerado un forastero andariego anual (Aguilar, 1989).

\section{Abril: La Pascua}

Se distingue cuatro Pascuas en la historia de la salvación: la Pascua del Señor, La Pascua de los Judíos, la Pascua de Cristo y la Pascua de la Iglesia (Cantalamessa, 2007), Esta última es recreada por los Licáneños, del 10 al 16 de abril. Se celebran las pascuas representadas por dos hermandades: La Santísima Virgen de los Dolores y el Señor de la Agonía. Las hermandades invitan a los 100 socios con quienes se conforman y brindan delicias gastronómicas como: encebollado de pescado, fanesca tradicional (hecha con zambo y zapallo como ingredientes esenciales). Arroz con papas cocinadas enteras y pescado frito. Chicha de Jora o avena de naranjilla, y las típicas canelas (bebida caliente realizada con agua de canela y naranjilla).

El presidente del GAD parroquial Licán, Sr. Pedro Brito, reconoce que es una fecha donde se ha perdido algo de la tradición ya que años atrás se acostumbraba, como parte de la procesión, el desfile de personas con escopetas formando un escuadrón de militares que disparaban a las alturas, pero lamentablemente sucedió un accidente por lo que nunca más se realizó esta actividad.

\section{Junio: Fiestas Patronales}

El 28 y 29 de junio en Licán se celebran las fiestas en honor al Patrono "San Pedro de Licán". En esta ocasión, se solicita a los amigos ofrendas para la preparación de la comida. Como referencia se menciona: 500 gallinas, 1 ganado como mínimo, 15 cerdos, entre otros. Se preparan las vísperas en la casa de los priostes, donde los bailarines llegan y son recibidos con un "caldo de fideo y pedazo de carne de res", luego se sirve "unas papitas con todas las vísceras utilizadas del ganado y el chancho", a esta preparación es parecida al contenido del "caldo de 31". Al día siguiente, la costumbre gastronómica es casi idéntica a la de la Fiesta de los Reyes, así como de la tomina como agradecimiento a los jochantes o colaboradores.

\section{Noviembre: Día de los difuntos}

El 2 de noviembre se celebra en honor a los difuntos. La población concurre a los cementerios, los deudos adornan tumbas de seres queridos con flores y tarjetas (Miro, 2006). Se prepara la tradicional colada morada con harina de maíz negro propio de la zona y con empanadas y 
"guaguas de pan". A esta tradición, se suma actividades como el juego de las bolas de acero conocidos como "los cocos".

\section{Diciembre: Navidad}

La Navidad, se celebra como una tradición anual, cuyo principal propósito es recordar el nacimiento de Jesucristo en Belén, según narran los evangelios de San Lucas y San Mateo (Sociedades Biblicas En America latina, 2014). Después de la misa del 24 de diciembre, se prepara una comida igual al día de Rey de Reyes. El 25 de diciembre, se celebra las fiestas principalmente con regalos para los niños, quienes se disfrazan de zachitas, vasallos y curiquingues. Se brinda como costumbre gastronómica buñuelos y dulce de higo.

\section{Discusión.}

Escasa es la información que existe sobre las fiestas de los puruhaes. Freire (2005) citando a Aquiles Pérez dice que las más importante fueron las siguientes: La fiesta de la cosecha, el nombre del hijo, La minga de la casa, la música y las danzas, costumbres familiares (matrimonios, nacimiento del niño, etc.)

Las festividades ecuatorianas abarcan, sino en su totalidad, celebraciones religiosas con abundante representación de lo andino y particularidades de cada lugar, así como fiestas con sus personajes propios; siendo este, el caso de Licán. Se pueden apreciar los reyes, los danzantes y éstos envueltos en las distintas ocasiones de un ambiente y decorado peculiar que rigen costumbres, tradiciones y ritos. Sin duda alguna son las bandas de pueblo (Coba A, 1996), las que no pueden faltar, pues son las que amenizan las fiestas (Estrella \& Suárez, 2016). Licán, es un lugar donde se caracteriza por sus festividades religiosas, deportivas, culturales y gastronómicas (Barahona, 2103)

El mundo de la gastronomía está constituido por una extensa variedad de culturas y costumbres. Estos elementos son de gran importancia para fortalecer la identidad de los pueblos. La humanidad determina dentro de la variedad de productos categorías de consumo pueden ser desde prohibido (no alimentos) hasta aquellos preferenciales de mayor estima, aquí es donde se sitúa la gastronomía, "cuya aceptación obedece especialmente a su carácter de referente que integra comunidades simbólicas y marca diferencias con otros grupos" (Hernández R, 2018).

Ecuador posee una riquísima, abundante y variada cultura gastronómica, que se encuentra fuertemente influenciada a lo largo de su historia (González, 1890), por los pueblos que conquistaron su territorio: (incas y españoles) y por migrantes que han llegado al país. La llegada de los Incas a nuestro territorio, seguramente ayudó a que el maíz adquiera mayor relevancia entre poblaciones indígenas de la sierra (Unigarra , 2014). La influencia de las variedades traídas por los españoles "como el trigo, la avena y el arroz; condimentos de dulce y de sal como el anís, y el ajo; carnes de cerdo, res, pavo y pollo" (Jacome G, 2008), permitieron mejorar el sabor y una vez combinados de manera armónica, son una delicia culinaria.

Es así que la gastronomía de la provincia de Chimborazo es una de las más diversas del país, debido a la gran variedad de materia prima existente en la provincia, mismos que influyen en una infinidad de platos apetecidos tanto por consumidores locales, nacionales y extranjeros. La 
trascendencia culinaria y los secretos del sabor transferidos entre familias por años de historia en la cocina, habla de la costumbre gastronómica del lugar (Morcia R, 2018)

Pedro Brito presidente de la junta parroquial de Licán en su memoria indica que "la costumbre gastronómica está estrechamente ligada a las fiestas", donde intervienen especies de crianza menores (Granizo G, 2017), como: cuyes conejos, gallinas, patos, pavos, gansos, en su mayoría utilizan para el autoconsumo. El chancho, el ganado también forman parte de la gastronomía, así como los productos cultivados en sus campos como el maíz, la papa (Martínez B, 2008), siendo un cultivo de prioridad en el Ecuador (Pumisacho \& Sherwood, 2002), entre otros. Las fiestas que son celebradas por el conjunto de los comuneros, sea en forma individual o comunal, momentos en los que vienen familiares del resto del país, constituyen ocasiones en las que el cuy siempre está presente en forma de comida o vivo (Laniado \& Echeverria, 1985)

En la Parroquia Licán las costumbres y tradiciones gastronómicas surgen del núcleo familiar. Los procedimientos en la elaboración de platos son transmitidos de generación en generación. Lastimosamente, en la actualidad, la vida de los habitantes de la parroquia es muy diferente a la que llevaron sus ancestros, quienes se dedicaban gran parte del día a la elaboración de los alimentos. Las preparaciones se convertían en cocciones largas mismas que se caracterizaban por sus texturas y sabores autóctonos.

Dentro del ámbito gastronómico sus ingredientes tienen fundamento histórico, tradición relacionada con fiestas, costumbres, ritos, religión, mitos, platos con antecedentes culturales, ligados a tiempos pasados, cosechas siembras como la chicha de jora (fiestas), fanesca (semana santa), chigüiles (carnaval), caldo de gallina, tortilla de papa, fritada, hornado, mote, chocolate (en tableta con agua) en la fiesta de reyes. Entre los productos cultivados actualmente en Licán está, la alfalfa, brócoli, tomate riñón, arveja, quinua, cebada, chocho, papa, hortalizas, frutales, frutilla, fréjol, pasto (PDOT Parroquia Lican, 2012)

La globalización y la innovación tecnológica han hecho que, las técnicas y equipos utilizados para sus preparaciones culinarias antiguas, vayan perdiendo sus raíces y sean sustituidas por equipos sofisticados que facilitan diversas preparaciones pero que no mantienen texturas y sabores tradicionales. Las tradiciones son practicadas con menor frecuencia y conforme pasan los años, se pierde la identidad propia (que los antepasados han transmitido por generaciones), adoptando tendencias foráneas.

\section{Conclusiones.}

- En la Parroquia rural Licán, pervive la memoria oral como forma de transmisión de los saberes ancestrales y prácticas culinarias, así como el interés por la conservación de algunas tradiciones, mediante la recreación contemporánea, como forma de enculturación dirigida a las nuevas generaciones; pese a que las prácticas culturales que han constituido la tradición del calendario agro festivo han disminuido o se han alterado notablemente. 
- La población, principalmente adulta, de la parroquia Licán, se halla arraigada a las costumbres, tradiciones y prácticas culinarias de sus antepasados; las cuales se manifiestan permanentemente en torno al calendario agro festivo y en estrecha relación con los productos que siembran y cosechan.

- Las costumbres gastronómicas de Licán se caracterizan principalmente por su relación con las fiestas, tradiciones, ritos, religión, mitos, platos con antecedentes culturales ligados a tiempos pasados, cosechas, siembras como la chicha de jora (fiestas), fanesca (semana santa), chigüiles (carnaval), caldo de gallina, tortilla de papa, fritada, hornado, mote, chocolate en tableta con agua en la fiesta de reyes, entre otros.

- La base de su alimentación se caracteriza por procedimientos, técnicas, y métodos de cocción, tradicionales, consolidados y actualizados, generación tras generación, sin embargo, debido a la adaptación de nuevas tecnologías, muchos de estos han sido reemplazados alterando elementos simbólicos de su gastronomía.

\section{Referencias Bibliográficas}

Aguilar, A. (1989). Nuestro Ecuador: Leyendas . Quito: Ministerio de Eduacación y Cultura.

Aguiló, F. (1985). El hombre de chimborazo (Cuarta ed.). Quito: Editorial Abya YAla.

Barahona, J. (2103). Elaboración del plan estratégico para el desarrollo turístico sostenible de la parroquia rural San Pedro de Licán del cantón Riobamba provincia de Chimborazo. Ambato: UTA. Obtenido de http://192.188.46.193/handle/123456789/4853

Bernal , C. (2016). Metodología de la Investigación (Cuarta ed.). Bogota: Editorial Pearson.

Camas, J. (2014). Fiesta la de los Reyes en la parroquia Licán del cantón Riobamba entre el 2010-2014. Riobamba: UNACH. Obtenido de http://dspace.unach.edu.ec/handle/51000/2480

Cantalamessa, R. (2007). La PAscua de Nuestra salvación (Primera ed.). s/c: San PAblo.

Carrillo, M. (1996). El sabor de la tradición: escenarios y actores de la cocina tradicional en el Centro Histórico de Quito. Quito: Abya-Yala.

Cisneros, G. (2017). El Rey de Reyes y el folclore popular. Obtenido de CCE Benjamien Carrión Nucleo del Chimborazo: https://www.culturaenecuador.org/artes/saberesancestrales/143-el-rey-de-reyes-y-folclor-popular.html

Coba A, C. (1996). Etnografía musical: bailes y danzas. Ritualismo y sacralización. s/c: Vervuert.

Estrella, E., \& Suárez, N. (2016). La fiesta de los reyes de Licán y su incidencia en los habitantes de la parroquia de Licán comprendidos de 28 a 40 años, en el período de 
enero 2005 a enero 2006. Riobamba: UNACH. Obtenido de http://dspace.unach.edu.ec/handle/51000/3333

Freire , C. (2005). Origen de los Puruhaes (Segunda ed., Vol. III). Riobamba: Editorial Pedagógica Freire.

GADPL. (2020). Licán: Ubicación Geográfica. Obtenido de Gobierno Autonomo descentralizado de la parroquia Licán : http://www.gadplican.gob.ec/

González , F. (1890). Historia General de la República del Ecuador. Quito: Publicaciones Educativas Ariel.

Granizo G, J. (2017). Diseño de un producto turístico para la parroquia Licán, cantón Riobamba, provincia de Chimborazo. Riobamba: ESPOCH. Obtenido de http://dspace.espoch.edu.ec/handle/123456789/7692

Hernández R, J. (2018). Cuando la alimentación se convierte en gastronomía. Procesos de activación patrimonial de tradiciones alimentarias. Cultura-hombre-sociedad. Cultura Hombre Y Sociedad, 28(1), 154-176. Obtenido de https://scielo.conicyt.cl/scielo.php?pid=S0719$27892018000100154 \&$ script $=$ sci_arttext\&tlng=n

INEC. (2010). Censo de Población y Vivienda 2010. Quito: INEC.

Jacome G, M. (2008). Tradición Culinaria Gualaceña. Revista 4 Sentidos, 3, 46-50. Obtenido de http://dspace.ucuenca.edu.ec/handle/123456789/30114

Küper, W. (1997). Pueblos indígenas y educación (Vol. 37). s/c: Abya-YAla.

Laniado , M., \& Echeverria, P. (1985). El cuy en la vida campèsina. Quito: INCCA.

Martínez B, J. (2008). Alimetación y cultura en el sur del Ecuador: la comida en el precerámico. Revista 4 Sentidos, 3, 34-40. Obtenido de http://dspace.ucuenca.edu.ec/handle/123456789/30112

Miro, M. (2006). Patrimonio Cultural de la Tradición de Finados. s/c: IPANC.

Morcia R, L. (2018). os clubes departamentales en Lima y la difusión de la cocina regional. Propuesta de un festival de cocinas regionales-2018. Lima: Universidad de san MArtin de Porres. Obtenido de http://repositorio.usmp.edu.pe/bitstream/handle/20.500.12727/4213/morcia_rfl.pdf?se quence $=3$

Moreno, S., Bustos L, G., Terán, N., \& Landázurí, C. (2008). Manual de Historia del Ecuador . Quito : Corporacoón Editora Nacional.

Münch, L., \& Angeles , E. (2015). Métodos y técnicas de Investigación (Quinta ed.). Buenos Aires: Trillas, S.A. de CV. 
PDOT Parroquia Lican. (2012). PLan de Desarrollo y ordenamiento territorial de la parroquia Lican. Lican: Semplades. Obtenido de http://www.gadplican.gob.ec/wpcontent/uploads/2018/04/PDOT-LICAN.pdf

Pumisacho, M., \& Sherwood, S. (2002). El cultivo de la Papa en Ecuador. Quito : AbyaYAla.

Sociedades Biblicas En America latina. (2014). La Biblia (Reina Vale). s/c: Holman Bible Publishers.

Tipán, M., \& Cando, P. (2017). Estudio de factibilidad del proyecto: crianza, producción y comercialización de cuyes como alternativa de mejoramiento de la situación socioeconómica de los moradores de la parroquia Lican, cantón Riobamba, provincia de Chimborazo. Quito: UCE. Obtenido de http://www.dspace.uce.edu.ec/handle/25000/9472

Unigarra , C. (2014). De la hacra al fogon. Quito: Ministerio de Cultura y Patrimonio.

Universidad de Texas. (2017). Ecuador, Guia Oficial de Turismo. s/c:

iPromomarketing.Corm,I S.A.

Urquizo A, M. (2017). Turismo religioso; difusión cultural de la fiesta “Rey de Reyes” en Lican-Riobamba, y su aporte al turismo de la parroquia. Quito: Instituto tecnológico Cordillera. Obtenido de http://www.dspace.uce.edu.ec/bitstream/25000/9472/1/TUCE-0005-006-2017.pdf 
PARA CITAR EL ARTÍCULO INDEXADO.

Moreno Guerra, A. M., Zurita Gallegos, R. M., \& Robalino Vallejo, J. A. (2020). Costumbres Culinarias de la Sierra Ecuatoriana . ConcienciaDigital, 3(3.1), 371-382. https://doi.org/10.33262/concienciadigital.v3i3.1.1442

\section{Ciencia \\ LDigital}

El artículo que se publica es de exclusiva responsabilidad de los autores y no necesariamente reflejan el pensamiento de la Revista Conciencia Digital.

El artículo queda en propiedad de la revista y, por tanto, su publicación parcial y/o total en otro medio tiene que ser autorizado por el director de la Revista Conciencia Digital.

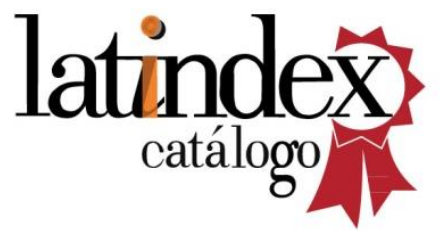

